\title{
THE TRACE ELEMENT ANALYSIS OF SINGLE DIAMOND CRYSTAL BY NEUTRON ACTIVATION ANALYSIS.
}

\author{
R.J. Hart ${ }^{*}$; A. Damarupurshad ${ }^{(1)^{*}} ;$ J.P.F. Sellschop ${ }^{(1)} ;$ H.O. Meyer ${ }^{(2)}$;M.E. McCallum ${ }^{(3)}$ and C. Koeberl ${ }^{(4)}$.
}

(1) Schonland research centre for Nuclear Physics, University of the Witwatersrand, Johannesburg; *Seconded from

the Geological Survey of South Africa; (2) Department of Geoscience, Purdue University, Lafayette, Indiana, 47907;

(3) Department of Earth Resources, Colorado State University, Fort Collins, Colorado, 80523; (4) Institute of

Geochemistry of Vienna, Vienna.

\section{Introduction}

The trace element geochemistry of natural diamonds or "diamond and its inclusion" provide valuable information on the environment in which diamonds crystallize. In addition such information may prove to be useful in "fingerprinting" diamonds of different provenence areas.

Existing data on the geochemistry of single diamond crystal are confined mainly to the geochemistry of inclusions in the diamond. ((Meyer and Boyd 1972) The development of the proton microprobe now makes it possible to measure the trace element contents in the diamond matrix itself. However, this technique has the serious drawback that the analysis is confined only to a narrow depth of 50 to 100 microns from the crystal surface and since the trace element content in a diamond may be zoned (Gurney 1991), this technique may not provide a true reflection of the bulk trace element geochemistry in diamond.

Potentially the most powerful technique for determining the bulk trace element content of a diamond is Neutron Activation Analysis (NAA). Previous studies in this field (Fesq et al. 1975, Erasmus et al. 1977 ) made use of $55 \mathrm{cc}$ intrinsic Ge(Li) detectors (peak to compton ratio of 40:1; efficiency of $10 \%$ ). The sensitivity of these detectors were not sufficient for the analysis of trace elements in a single diamond crystal and composite samples of between 10 and 20 stones (total $1 \mathrm{gm}$ ) were analysed. This provided information only on the average chemistry of a group of stones. Improvement in detector technology over the last decade has led to the development of large volume (199cc) $\mathrm{Ge}(\mathrm{Li})$ detectors ("Monster" detectors) with an improved peak to compton ratio of $72: 1$ and an efficiency of $40 \%$. With this detector and improved counting electronics, we have been able to achieve up to a 5 fold increase in sensitivity which now enables us to quantitatively analyse trace elements in small single crystals.

\section{Sample selection}

Thirty-five diamonds both with and without visible inclusions have been selected for trace element analyses by NAA. Ten of the samples are from the George Creek mine in Colorado, nine samples are from a mine near Romaria in Brazil and ten samples are from the Finsch mine in South Africa. The diamonds range in weight from .01 to 0.2 carats and any inclusions are generally less than 10 microns in size. The diamonds also vary considerably in colour and quality, from black to gem quality white.

\section{Experimental procedure}

The diamonds were irradiated in an Oak Ridge type reactor at Pelindaba (South Africa) for ten days, and are then counted 17 hours, 3 days, 12 days, 30 days and 3 months after irradiation. Counting times employed were 6 hours for the first count, and then for 24 hours for each of the subsequent counts. It is important to make sure that the gamma signal counted on the detector comes from the body of the diamond and not from any residual surface contamination, and special care was taken in the cleaning of the diamonds prior to irradiation: the diamonds are boiled individually in a concentrated mixture of $\mathrm{HNO}_{3}, \mathrm{HClO}_{4}$ and $\mathrm{H}_{2} \mathrm{SO}_{4}$ for 1 hour before encapsulation in a quartz vial and on post irradiation removal, the procedure is repeated. The total neutron flux received by each sample was measured by using a flux monitor in the form of steel wire wrapped around the outside of the vial. Background counts were performed regularly throughout the experiment. 
Quantitative data; precision and accuracy

Diamonds are particularly well suited to the technique of NAA as the carbon matrix is "transparent" to neutrons and the diamonds have a very low background count. In order to quantify the trace element data in single crystal diamonds it was essential to develop suitable standard material with trace element concentrations and matrix that is comparable to diamond. In this study it was found that a 50:1 mixture of "specpure" graphite with standard rock powders provided us with suitable reference material, although the concentrations of most elements in the standards are still higher than those found in most diamonds. Large volumes of these mixed standards were analysed both at the Schonland Centre, University of the Witwatersrand and at the Institute of Geochemistry, University of Vienna. The interlaboratory comparisons and replica analyses (see Table 1) provide us with a measure of the accuracy and precision of our analyses at ppb levels.

Table 1. A comparison of data for graphite standard from University of Vienna and the Schonland centre. Except where stated values given in $\mathrm{ppb}$

$\begin{array}{lcccc}\text { Element } & \begin{array}{c}\text { Vienna } \\ \text { mean }\end{array} & \begin{array}{c}\text { Schonland n } \\ \text { mean }\end{array} & \text { Std. Dev. } \\ \text { La } & 60 & 86 & 8 & 30 \\ \mathrm{Na} \mathrm{ppm} & 100 & 96 & 8 & 12 \\ \mathrm{Br} & 120 & 68 & 8 & 12 \\ \mathrm{As} & 70 & 53 & 8 & 8.8 \\ \mathrm{Sm} & 12 & 15 & 8 & 5.9 \\ \mathrm{Au} & 14 & 8 & 8 & 9.5 \\ \mathrm{U} & 5 & 11 & 4 & 6.6 \\ \mathrm{Nd} & 100 & 110 & 2 & 1.4 \\ \mathrm{Ba} \text { ppm } & 6 & 12 & 7 & 11 \\ \mathrm{Lu} & 5 & 2 & 3 & 2.1 \\ \mathrm{Yb} & 20 & 28 & 5 & 13 \\ \mathrm{Ce} & 110 & 177 & 4 & 44 \\ \mathrm{Cr} \text { ppm } & 108 & 130 & 9 & 23 \\ \mathrm{Eu} & 35 & 112 & 4 & 9.6 \\ \mathrm{Co} p \mathrm{ppm} & 2.3 & 2.9 & 8 & 1.4 \\ \mathrm{Fe} \% & 0.17 & 0.11 & 7 & 0.5 \\ \mathrm{Ta} & 17 & 18 & 8 & 1.4 \\ \mathrm{Sc} & 460 & 803 & 8 & 11 \\ \mathrm{Ni} \text { ppm } & 55 & 72 & 8 & 17 \\ \mathrm{~Tb} & 20 & 13 & 4 & 8.1 \\ \mathrm{Cs} & 50 & 43 & 6 & 8.8 \\ \mathrm{Hf} & 20 & 25 & 4 & 13 \\ \mathrm{Ir} & 1.4 & 1.9 & 6 & 0.6 \\ \mathrm{~W} & 40 & 43 & 7 & 23 \\ \mathrm{Th} & 15 & 20 & 7 & 3.4 \\ & & & & \end{array}$

\section{Discussion}

All the diamonds thus far analysed contain some trace elements and each individual stone has its own trace element characteristics. This strongly emphasises the need to analyse individual stones rather than composite samples. As expected, clear white diamonds contain only few elements and always at low abundances, whereas stones with inclusions or with deep colour contain relatively high abundances of trace elements. Black diamonds contain almost all the elements listed in Table1. In all cases, if the diamond contains an identifiable inclusion, the geochemistry reflects that inclusion.

\section{Trace element geochemistry in relation to environment of crystallization}

In most cases the geochemistry of the diamonds is dominated by siderophile elements and all the indications from this study are that the chemistry of the siderophile elements reflects the environment in which the diamonds crystallized. For example the $\mathrm{Au} / \mathrm{Ir}$ ratios in two of the diamonds from Finsch (Fig. 1) plot close to the mantle line and are consistent with Au/Ir ratios in diamond obtained by Fesq et al. (1975). It is interesting to note that many of the diamonds thus 
far analysed contain Au irrespective of whether or not there is an inclusion such as sulphide which may host $\mathrm{Au}$, suggesting that $\mathrm{Au}$ in diamond may exist in the metallic form.

Plots of Fe versus $\mathrm{Cr}$, and $\mathrm{Fe}$ versus Sc are shown in Fig. 2 and 3. The data shown in these plots represent diamonds both with and without visible inclusions. Clearly the Finsch diamonds can be separated into the two major parageneses found in diamond inclusions. The samples with high $\mathrm{Cr}$ and high Sc content both have visible peridotitic garnet inclusions, whereas the remaining Finsch diamonds (two of which have eglogitic clinopyroxene inclusions) all have lower $\mathrm{Cr}$ and Sc contents and plot in separate fields in Fig. 2 and 3. Furthermore, there are indications that both groups of Finsch diamonds have a different signature to the diamonds from North And South America; these have a more restricted geochemistry which is strongly influenced by $\mathrm{Fe}$.

\section{Trace element Geochemistry in relationship to provenance area}

Some diamonds are also relatively enriched in lithophile elements The chondrite normalized REE patterns for these stones are shown in Fig.4. Clearly the REE patterns for the three suites of diamonds analysed in this study are significantly different. Moreover, the fact that in each case there are two diamonds from each suite with similar patterns provides some measure of confidence in these analyses of REE at ppb levels.

Samples F10 and GC1 are both black diamonds with no visible inclusions or cracks, but the four remaining diamonds range from brown to colourless and are characterised by micro-cracks which contain tiny specks of material. Thus although the REE could be located in the body of the diamond, our interpretation is that these LREE enriched patterns reflect contamination of the diamond by the host kimberlite. In conclusion, we suggest that the lithophile elements (and in particular the REE) tell us more about the kimberlite event rather than about the crystallization environment of diamonds.

\section{Conclusions}

The application of NAA technique to small ( $<0.2$ carats) single crystal diamonds clearly illustrates the ability to analyse trace elements in diamonds down to ppb for some elements. Ultimately such information must prove useful in 1) understanding the origin of diamonds 2) relating diamonds to their source area, and 3 ) other facets of the diamond industry such as the use of diamonds as semi-conductors.

\section{References}

Erasmus C.S., Sellschop J.P.F., Bibby D.M., Fesq H.W., Kable E.J.D. Keddy R.J., Hawkins D.M., Mingay S.E., Rasmussen S.E., Renan M.J. and Watterson J.I.W. 1977. J. Radioanal. Chem. 38, 133-146.

Fesq H.W., Bibby D.M., Erasmus C.S., Kable E.J.D., Sellschop J.P.F. 1975. Phys. Chem. Earth, 9, 817-836.

Gurney J.J. 1991. S. Afr. J. Geol. 93(3), 424-437.

Meyer H.O.and Boyd F.R. 1972. Geochimica et Cosmochimca Acta, 36, 1255-1273.

Tredoux M., De Wit M.J., Hart R.J. Lindsay N.M. Verhagen B. and Sellschop J.P.F. J. Geology, 97, 589-605. 


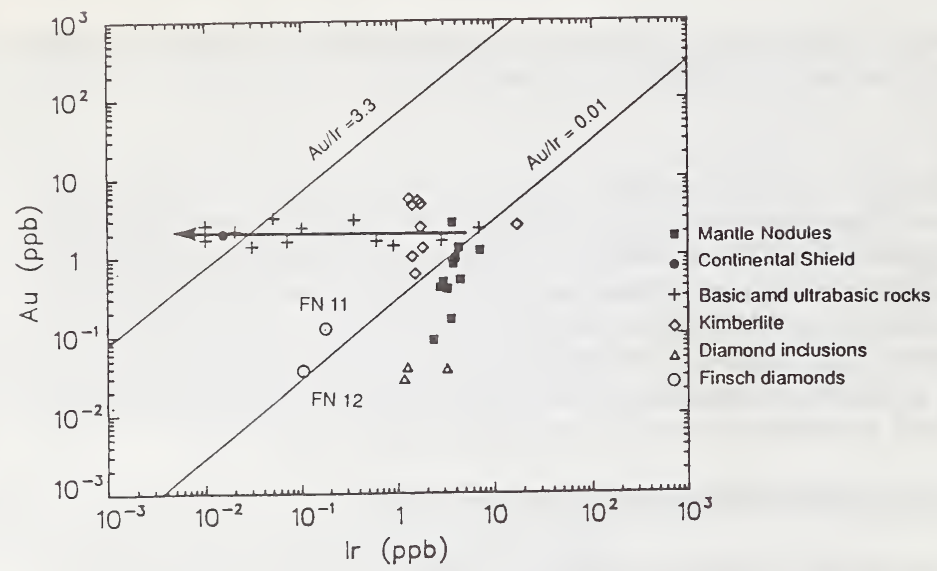

Fig. 1 A comparison of the $\mathrm{Au} / \mathrm{Ir}$ ratio for two of the Finsch diamonds to various mantle derived rocks. the arrow shows the mantle $(\mathrm{Au} / \mathrm{Ir}=0.01)$ Crust (Au/Ir = 3.3) differentiation trend. (After Tredoux et. al 1989)

Fig. 2,3 Plots of $\mathrm{Fe}$ versus $\mathrm{Cr}$ and $\mathrm{Fe}$ versus $\mathrm{Sc}$ respectivly. The horizontal shading represents the field for the North and South American Diamonds, the vertical shading represents the field for the Finsch peridotitic diamonds and the dotted shading the field for the Finsch eglogitic diamonds.
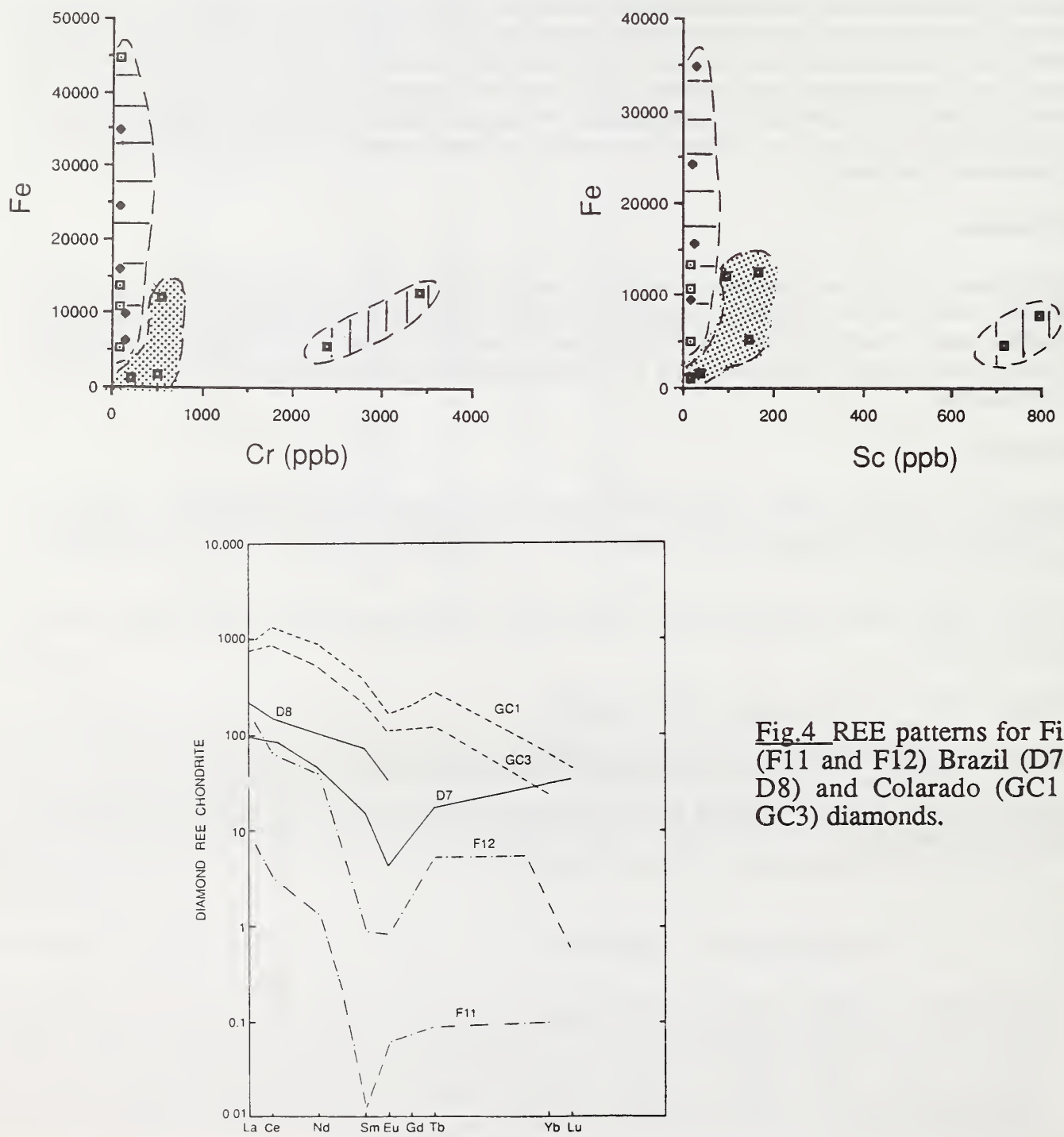

Fig. 4 REE patterns for Finsch (F11 and F12) Brazil (D7 and D8) and Colarado (GC1 and GC3) diamonds. 